\title{
AVALIAÇÃO DOS CONHECIMENTOS TEÓRICOS DOS DIABÉTICOS DE UM PROGRAMA INTERDISCIPLINAR
}

\author{
Henriqueta Galvanin Guidio de Almeida * \\ Olga Chizue Takahashi ** \\ Maria do Carmo Lourenço Haddad *** \\ Maria Helena Dantas de Menezes Guariente ${ }^{\star \star \star}$ \\ Maria Leocádia de Oliveira ${ }^{\star \star \star *}$
}

\begin{abstract}
Através de um instrumento de avaliação de conhecimentos, as autoras testaram a capacidade de compreensão e memorização de dez grupos de diabéticos atendidos por uma equipe multiprofissional que atua no ambulatório do Hospital Universitário Regional do Norte do Paraná. A avaliação incluiu temas diversos que faziam parte das atividades do programa educacional. Somente um grupo de pacientes apresentou índices de acerto considerados adequados. Analisados individualmente, diabéticos jovens, motivados e com bom nível de compreensão obtiveram melhores resultados. Conclui-se que a avaliação possibilitou identificar pacientes que necessitam de reforços nas diversas áreas de conhecimento permitindo a programação de atividades específicas para os mesmos.
\end{abstract}

UNITERMOS: diabetes, avaliação, interdisciplinariedade, educação, conhecimento

\footnotetext{
* Médica; Professor-Adjunto do Departamento de Clínica Médica da Universidade Estadual de Londrina; Coordenadora do Ambulatório Interdisciplinar de Diabetes do Hospital Universitário de Londrina

** Enfermeira; Professor-Adjunto do Departamento de Enfermagem da Universidade Estadual de Londrina; profissional do Ambulatório Interdisciplínar de Diabetes do Hospital Universitário de Londrina; vice-coordenadora do Colegiado do Curso de Enfermagem e Obstetrícia da Universidade Estadual de Londrina

*** Enfermeira; Professor-Assistente do Departamento de Enfermagem da Universidade Estadual de Londrina; profissional do Ambulatório Interdisciplinar de Diabetes do Hospital Universitário de Londrina

**** Médica; Professor-Adjunto do Departamento de Clínica Médica da Universidade Estadual de Londrina, profissional do Ambulatório Interdisciplinar de Diabetes do Hospital Universitário de Londrina
} 


\section{INTRODUÇÃO}

A educação em saúde é considerada como parte integrante do tratamento das doenças crônicas ${ }^{1,3,4,8,9,13,16}$. É através dela que o indivíduo consegue adaptar seu "Modus Vivendi" frente à nova situação que a doença lhe impõe. Novos hábitos e atitudes são desafios constantes a serem adquiridos, com o objetivo de se alcançar uma sobrevida maior, mais saudável e livre de complicações ${ }^{2,5,7,10,12,17}$.

Em nosso meio, principalmente a partir da década de 80 , vem crescendo o número de publicações versando sobre educação e doenças crônicas ${ }^{3,4}$. Entre estas ocupa posição destacada o Diabetes Mellitus, em cujo tratamento a participação ativa do paciente se toma essencial ${ }^{1,5,7,8,10,14,17}$.

As experiências de equipes multiprofissionais e colônias de férias para pacientes crônicos têm desempenhado importante papel como estratégias educacional consideradas eficientes ${ }^{1,5,7,15,17}$.

O processo educativo é complexo e envolve várias fases em seu desenvolvimento. Entre estas, inclui-se o entendimento e memorização de conteúdos, como passo precedente e motivador da mudança de hábitos de vida que é etapa final e conclusiva do processo educacional ${ }^{6,11,15}$.

A avaliação do método educativo é tarefa difícil abrangendo a avaliação de parâmetros diversos e os relatos de experiências nesta área em nosso meio são escassos $^{6,7}$.

Em 1984, um grupo de profissionais constituídos por médico, enfermeiro, psicólogo, nutricionista e assistente social, implantou um Programa de ATENDIMENTO AMBULATORIAL INTERDISCIPLINAR AO DIABÉTICO (P.A.A.I.D.) no Hospital Universitário Regional do Norte do Paraná (H.U.R.N.Pr.) com os objetivos de educar o paciente e familiares, treinar alunos e profissionais no cuidado ao diabético.

Inicialmente o processo educacional adotado foi o de aulas teórico-práticas formais ministradas em grupos, onde cada profissional expunha o conteúdo de sua especialidade.

Passada a fase de implantação, verificou-se que este processo não atingiu os objetivos propostos, sendo adotado outros métodos de ensino, tais como esclarecimento de dúvidas dos grupos, orientações e treinamentos individuais, aulas programadas de acordo com a solicitação dos pacientes, vivências em passeios e piqueniques.

Considerando essas diversas formas de ensino utilizadas no programa, a equipe sentiu a necessidade de avaliar o grau de conhecimento adquirido por esses diabéticos para redirecionar o processo educativo.

Neste contexto e no sentido de contribuir para a reflexão sobre o dimensionamento da eficiência do método educativo, os autores apresentam este estudo. 


\section{OBJETIVOS}

Este trabalho tem os seguintes objetivos:

- Avaliar a memorização dos pacientes sobre os conteúdos teórico-práticos ministrados durante o processo educativo.

- Selecionar individual e grupalmente diabéticos com deficiências de conhecimentos teóricos.

- Identificar as áreas de conhecimento deficientes.

- Planejar as discussões e reforços destes conteúdos com pacientes e grupos indicados pela avaliação.

\section{METODOLOGIA}

Os dados foram levantados através de um instrumento do tipo questionário contendo 82 questões, abertas e fechadas, distribuídas em onze parte, sendo que cada parte abordou o conteúdo das diversas áreas de conhecimento relacionadas ao diabetes mellitus e foram assim ordenadas; dados de identificação, 5 questões sobre higiene corporal, 9 sobre exercício físico, 19 sobre aplicação de insulina e hipoglicemiantes orais, 11 sobre automonitorização, 19 sobre noções da doença, 13 questões sobre nutrição, 4 sobre aspectos sociais do diabético, 2 sobre a opinião do paciente a respeito do programa, impressões do entrevistador e sugestões sobre o questionário. (ANEXO I).

Para verificar a viabilidade do instrumento, foi realizado um teste piloto com 10 pacientes, verificando-se a necessidade de realizar algumas modificações na redação de 5 perguntas.

O instrumento foi aplicado no primeiro semestre de 1993 para 111 diabéticos atendidos no programa interdisciplinar, pertencentes a 10 grupos e 19 pais de crianças e adolescentes diabéticos, que freqüentavam o programa há pelo menos 1 ano.

Os grupos foram formados considerando-se o tipo de diabetes, grau de instrução e idade, com a finalidade de propiciar trocas de experiências e facilitar o Processo Educacional.

As respostas foram obtidas com o próprio cliente assinalando ou escrevendo, ou com o auxílio dos profissionais e estagiários de Enfermagem que liam as proposições e assinalavam as respostas obtidas nos casos de dificuldade de compreensão, de indivíduos analfabetos ou com deficiência física.

Do total de 80 questões, somente 59 foram motivo de avaliação conjunta, as demais, por apresentarem características individuais dos pacientes, não foram 
passíveis de computação objetiva, mas sim de apreciação individual (Exemplo: tipo de exercício praticado, tipo de tira reagente na monitorização, motivos para não auto aplicação de insulina, aspectos sociais, etc.).

Considerou-se que pacientes que obtivessem $70 \%$ de acerto, tinham conhecimento suficiente do assunto. Diabéticos com índices inferiores receberiam reforço dos conteúdos deficientes.

\section{RESULTADOS E DISCUSSÃO}

O instrumento foi respondido por 87 (78\%) diabéticos, e 13 (68\%) pais de crianças e adolescentes diabéticos, que compareceram nos retornos, conforme é apresentado no Quadro I.

QUADRO I - CARACTERÍSTICAS DOS GRUPOS DE DIABÉTICOS E PAIS DAS CRIANÇAS E ADOLESCENTES DIABÉTICOS DO P.A.A.I.D./H.U.R.N.Pr.

\begin{tabular}{|c|c|c|c|c|c|c|}
\hline $\begin{array}{r}\text { Características } \\
\text { dos Grupos }\end{array}$ & $\begin{array}{c}\text { Número total } \\
\text { de pacientes } \\
\text { e pais }\end{array}$ & $\begin{array}{c}\text { Númer } \\
\text { pacient } \\
\text { entrel } \\
N^{\circ}\end{array}$ & $\begin{array}{c}\text { ro e } \% \text { de } \\
\text { tes e pais } \\
\text { vistados } \\
\%\end{array}$ & Idade & $\begin{array}{c}\text { Nível de } \\
\text { compreensão }\end{array}$ & $\begin{array}{l}\text { Insulinode- } \\
\text { pendente }\end{array}$ \\
\hline I & 13 & 13 & -100 & Adulto Jovem & Bom & Sim \\
\hline II & 11 & 10 & -91 & Adulto Jovem & Bom & Sim \\
\hline III & 12 & 12 & -100 & Variada & Baixo & Sim \\
\hline IV & 07 & 06 & -86 & Crianças & Bom & Sim \\
\hline $\mathrm{V}$ & 15 & 07 & $\begin{array}{l}-\quad 47 \\
\end{array}$ & Idosos & Regular & Não \\
\hline VI & 14 & 10 & -71 & Idosos & Regular & Não \\
\hline VII & 12 & 12 & -100 & Adolescentes & Bom & Sim \\
\hline VIII & 08 & 06 & -75 & Variado & Regular & Sim \\
\hline IX & 11 & 08 & -73 & Variado & Regular & Sim \\
\hline$x$ & 09 & 03 & $-\quad 34$ & Adulto Jovem & Bom & Sim \\
\hline Pais Grupo IV & 07 & 07 & - 100 & Variado & Bom & Não \\
\hline Pais Grupo VII & 12 & 06 & -50 & Variado & Bom & Não \\
\hline Total & 130 & 100 & -100 & -------- & -------- & -------- \\
\hline
\end{tabular}

Os pacientes não avaliados não responderam ao questionário, por motivos variáveis como: falta á consulta, idade insuficiente, dificuldade de tempo. 
Dos 10 grupos de diabéticos em que o questionário foi aplicado 08 são de pacientes em dependência de insulina e 2 de insulinoindependentes.

Cinco grupos de pacientes tinham idade menor que 30 anos, todos com diabetes do tipo I ou insulinodependente e todos apresentavam bom nível de compreensão, dois grupos eram de pacientes mais idosos, com Diabetes Mellitus do tipo II, não insulinodependentes e com nível de compreensão regular. Os três grupos restantes tinham idade variada, com predomínio de pacientes malores de 35 anos. 0 nível de compreensão aqui era de regular para baixo e os pacientes eram portadores de diabetes tipo I ou II com insulinodependência.

As porcentagens de acerto das questões propostas para os 10 grupos de diabéticos e 2 grupos de pais são mostradas no Quadro II.

QUADRO II - PERCENTAGEM (\%) DE ACERTOS AS QUESTÕES PROPOSTAS AOS DIVERSOS GRUPOS DA P.A.A.I.D.IH.U.R.N.Pr

\begin{tabular}{|c|c|c|c|c|c|c|}
\hline $\begin{array}{r}\text { Resultados } \\
\text { (\%) }\end{array}$ & $\begin{array}{c}\text { Higiene } \\
\text { Corporal }\end{array}$ & $\begin{array}{c}\text { Exercício } \\
\text { Físico }\end{array}$ & $\begin{array}{c}\text { Uso de } \\
\text { insulina e } \\
\text { Hipoglice- } \\
\text { miantes orais }\end{array}$ & $\begin{array}{c}\text { Autonomi- } \\
\text { torização }\end{array}$ & $\begin{array}{c}\text { Noções } \\
\text { gerais } \\
\text { sobre o } \\
\text { diabetes }\end{array}$ & Nutrição \\
\hline Grupo I & 78,4 & 68,2 & 76,9 & 74,7 & 67,4 & 67,4 \\
\hline Grupo II & 86,0 & 62,5 & 66,6 & 61,4 & 65,8 & 70,0 \\
\hline Grupo III & 73,3 & 62,5 & 56,4 & 53,5 & 53,9 & 44,8 \\
\hline Grupo IV & 56,6 & 50,0 & 57,4 & 47,6 & 50,9 & 43,5 \\
\hline Grupo V & 57,1 & 44,6 & 19,0 & 26,5 & 32,7 & 38,4 \\
\hline Grupo VI & 72,0 & 60,0 & 26,6 & 48,5 & 44,7 & 46,9 \\
\hline Grupo VII & 83,3 & 66,6 & 71,2 & 58,3 & 60,7 & 65,3 \\
\hline Grupo VIII & 70,0 & 33,3 & 61,1 & 40,4 & 49,0 & 43,5 \\
\hline Grupo IX & 75,0 & 54,6 & 62,5 & 44,6 & 52,9 & 53,8 \\
\hline Grupo X & 100,0 & 75,0 & 74,0 & 71,4 & 72,5 & 71,7 \\
\hline Pais Grupo IV & 30,0 & 51,7 & 60,3 & 63,2 & 58,8 & 68,1 \\
\hline Pais Grupo VII & 83,3 & 54,1 & 70,3 & 57,1 & 54,9 & 65,5 \\
\hline
\end{tabular}

Quanto ao assunto higiene corporal, verifica-se que com exceção dos grupos IV e $\mathrm{V}$ todos obtiveram um índice acima de $70 \%$. Esses resultados foram os esperados considerando que este tema é discutido com o paciente em todos os retornos e também por ser um hábito já adquirido pelo diabético. Julga-se que os índices obtidos no grupo IV devem-se a pouca idade das crianças e ao fato de que os cuidados de higiene ainda são de responsabilidade dos pais. Quanto ao grupo V, observa-se que este resultado pode estar relacionado a faixa etária mais avançada e ao baixo nível de compreensão destes pacientes. 
Analisando-se as respostas individuais, verificou-se que o número de erros foi maior nos itens sobre periodicidade da visita ao dentista. Este resultado demonstra a falta de hábito desses diabéticos, como também da população em geral, em freqüentarem o dentista periodicamente. O outro item que obteve um índice de acerto pequeno foi sobre a importância do banho diário, o que causou surpresa, pois todos relataram que tomam banho, mas poucos conhecem a importância desse hábito para o diabético.

Quanto ao exercício físico, verificou-se que somente o grupo $X$ atingiu o índice de acerto estipulado como bom. Este grupo ainda está em formação, e é composto por 3 diabéticos jovens, de boa compreensão e com diagnóstico recente. Nos grupos restantes observa-se um índice de acerto menor.

$\mathrm{Na}$ análise individual das respostas, dos 87 pacientes que responderam 0 questionário, a maioria afirmou que realiza exercício físico, sendo que 42 referem caminhadas, 12 outras atividades físicas e os mais jovens praticam até duas modalidades de esportes. Desses pacientes, 39 referem exercitar-se mais de uma hora por dia durante 3 vezes na semana e 35 tomam os cuidados antes da realização do exercício físico.

Observa-se que apesar dos diabéticos referirem realizar esta atividade, contradisseram-se quando responderam as questões que justificavam a importância e os cuidados necessários na realização do exercício, conforme apresentado no Quadro II, refletindo que este hábito ainda não foi incorporado no seu cotidiano.

Em relação a aplicação de insulina, verificou-se que os grupos I, VII, X e os pais dos adolescentes atingiram um índice de acerto acima de 70\%, o que era esperado, em função do maior grau de compreensão desses indivíduos.

Dos 87 pacientes entrevistados, 70 eram insulinodependentes, dos quais 56 referem fazer auto-aplicação da insulina, sendo que 7 não executam a técnica por medo e 5 são crianças menores de 8 anos de idade.

Quanto ao rodízio, observou-se que 65 dos pacientes utilizam o abdômen, a coxa e o glúteo para auto-aplicação; 38 responderam corretamente a justificativa sobre a necessidade do rodízio.

O método de conservação do material para auto-aplicação foi citado corretamente por 50 pacientes.

Dos indivíduos insulinodependentes, 54 nunca suspenderam o uso da insulina e as principais justificativas para a suspensão foram por hipoglicemias, glicosúrias negativas, falta de medicação.

Com a análise destes dados verifica-se que apesar dos pacientes e pais serem treinados individualmente, ainda apresentam dificuldades e várias dúvidas sobre a aplicação da insulina que pode estar associada a não aceitação da doença, como também pelas próprias dificuldades do indivíduo em compreender o assunto.

O Quadro II também apresenta o percentual de acerto sobre as questões relativas a automonitorização. Verificou-se que somente 42 pacientes conhecem o valor da glicemia de jejum, apesar desses índices serem comentados com os 
diabéticos em todos os retornos, no momento da verificação da glicemia de polpa digital. Percebe-se que os mesmos não correlacionam a taxa da sua glicemia com os valores normais.

Observou-se também que 36 pacientes informaram realizar a glicosúria no domicílio de 1 a 3 vezes por semana, embora poucos tragam o registro, como é solicitado nos retornos. Os que executam a automonitorização compram as fitas reagentes, e a justificativa dada pelos que não realizam esse procedimento é o alto custo do material, 70 diabéticos relataram que este controle não os incomoda e é importante para o controle da doença.

Quanto ao conteúdo Noções Gerais sobre os Diabetes, observou-se que com exceção do grupo $X$, todos os demais não conseguiram atingir o índice de acerto considerado ideal, mesmo os grupos que freqüentam o programa há mais de 6 anos, como é o caso dos grupos I, II, III, V e VI. Este resultado surpreendeu a equipe, pois este assunto é de domínio dos profissionais e é explicado formalmente em aulas teóricas programadas durante o ano e informalmente todas as vezes que o paciente apresenta dúvidas ou solicita informação detalhada.

Acredita-se que este resultado esteja relacionado com a aceitação da doença pelo diabético, que de uma maneira geral, prefere não conhecer a morbidade que a patologia pode provocar. Esta constatação também é citada por outros autores $8,10,12,14$.

Em relação ao conteúdo sobre nutrição, verificou-se que somente o GRUPO I e o GRUPO X atingiram um índice de acerto bom. Este resultado demonstra que uma das maiores dificuldades do diabético é adotar uma dieta adequada a sua necessidade. Embora a nutricionista atenda individualmente os pacientes nos retornos dos grupos e programe retornos semanais, para pacientes com maiores dificuldades, sempre considerando em suas orientações as condições sócioeconômicas do diabético, os resultados foram pouco satisfatórios.

Com relação aos resultados apresentados é importante considerar em primeiro lugar o nível de compreensão dos pacientes, constatado como regular ou baixo em metade dos grupos de diabéticos, o que dificulta muito a atividade educacional. Os grupos $\mathrm{V}$ e $\mathrm{VI}$ constituem dois dos grupos mais antigos do programa. Embora esperados bons índices de acerto pela convivência antiga com as atividades educacionais, estes pacientes apresentaram resultados pouco satisfatórios.

Foram considerados fatores contribuitórios para isto, o baixo nível de compreensão e a idade avançada dos pacientes que diminui sua motivação e expectativa de vida.

Por outro lado, o grupo I também antigo, mas com pacientes com melhor nível de compreensão, mais jovens, mais motivados, obteve melhores resultados.

A aplicação prática dos conteúdos também é observada como um bom motivo de entendimento e memorização dos mesmos. Diabéticos do tipo II, insulinoindependentes, conhecem pouco assuntos como insulinoterapia, auto monitorização domiciliar porque em geral estes conteúdos não repercutem em ações na sua vida diária. 
Os resultados observados nos grupos das crianças, não alcançaram as metas desejáveis apesar do bom nível de compreensão destes pacientes. Aqui há que se considerar a baixa idade e o pouco tempo de freqüência no programa, como justificativas aceitáveis, o índice de acerto às questões melhora quando se avalia o grupo de pais destas crianças.

\section{CONSIDERAÇÕES FINAIS E CONCLUSÃO}

A aplicação do questionário de avaliação do conteúdo teórico ministrado aos pacientes do Programa Ambulatorial Interdisciplinar ao Diabetes/H.U.R.N.Pr. ocorreu em uma fase em que a equipe de profissionais vinha propondo uma reformulação global desta atividade educativa. Para tanto considerou-se como passo inicial a avaliação individual e grupal dos pacientes com relação à conteúdos ministrados anteriormente.

A apreciação dos resultados permitiu identificar que:

- Em todos grupos entrevistados com exceção do X (em todas as áreas) e do I (em metade das áreas) a percentagem satisfatória de acertos as questões foi muito baixa.

- Os grupos IV e V não acertaram 70\% das questões em nenhuma área.

- A higiene corporal mostrou-se como assunto suficientemente conhecido em todos os grupos.

- As questões sobre o uso de hipoglicemiantes orais e insulina foram respondidas adequadamente em 04 grupos.

- São pouco conhecidos os assuntos sobre nutrição e automonitorização que alcançaram índices satisfatórios de acerto em 2 grupos cada; noções gerais sobre 0 diabetes e exercício físico obtiveram índice satisfatório de acerto em 1 grupo cada.

- A análise das respostas de cada entrevistado leva a conclusões semelhantes às obtidas na análise grupal.

Estes resultados foram discutidos com os diabéticos, decidindo-se por uma abordagem educacional que inclua ações individuais e grupais.

Os temas básicos sobre o diabetes foram agrupados para serem discutidos com os pacientes em 04 sessões mensais e consecutivas. A técnica utilizada será a expositiva, com cartazes, slides e demonstrações práticas e a forma de abordagem será grupal. As ações planejadas a partir de dificuldades específicas de cada paciente serão desenvolvidas de forma individual durante as fases do seu atendimento. Embora a equipe acredite que a aquisição do conhecimento não é garantia de aplicação dos mesmos na vida diária, a mudança dos hábitos de vida requer tempo, conscientização e aceitação da doença. 


\section{EVALUATION OF DIABETES' CARRIERS THEORETICAL KNOWLEDGE IN AN INTERDISCIPLINARY PROGRAM}

Using an instrument of evaluation of theoretical knowledge, the authors have assessed the capacity of understanding and memorizing often groups of diabetes' carriers that were being followed by a multiprofessional team from the ambulatory of the HURNP. The evaluation included the discussion of a variety of subjects which were part of the activities of an Educational Program. Only one group of patients showed a satisfactory performance. Individual analysis showed that young diabetes' carriers, that were motivated and had good level of understanding, had a better performance. It was concluded that the evaluation allows the selection of patients that need specific reinforcement and that a plan of activities can be elaborated according to the tested subjects.

UNITERMS: diabetes, assessment, interdisciplinary, education, knowledge

\section{EVALUACIÓN DE LOS CONOCIMIENTOS TEÓRICOS DE LOS DIABÉTICOS EN UN PROGRAMA INTERDISCIPLINAR}

A través de un instrumento de evaluación, los autores testaron la comprensión y memorización de diez grupos de diabéticos atendidos por un equipo multiprofesional con, respecto a temas diversos con ellos discutidos durante las actividades de un programa educacional. Solamente un grupo de pacientes obtuvo índices de acierto considerados adecuados. Analizados individualmente diabéticos jóvenes, motivados y con buen nivel de comprensión alcanzaron mejores resultados. Se concluye que la evaluación permitió seleccionar pacientes a los cuales los refuerzos en las diversas áreas de conocimiento testadas deben ser planeadas.

UNITERMOS: diabetes, evaluación, educación, conocimiento

\section{REFERÊNCIAS BIBLIOGRÁFICAS}

01. ALMEIDA, H.G.G. Educação em diabetes: a experiência da equipe do Hospital Universitário Regional do Norte do Paraná. In: ENCONTRO NACIONAL DE EDUCAÇÃO EM DIABETES, 2, 1988. Florianópolis. Anais. Florianópolis: SBEM-SC, 1988. p. 109-17.

02. ANDERSON, R. M. et al. Learning to empower patients. Results of professional education program for diabetes educators. Diabetes Care, v. 14, n. 7, p. 590, jul. 1991. 
03. BRASIL. Ministério da Saúde. Secretaria Nacional de Programas Especiais de Saúde e Divisão Nacional de Doenças Crônico-Degenerativas. Plano nacional de educação e controle do diabetes mellitus. Brasília: Ministérios, 1988. p.47.

04. CASTELAR, R. Sessão de abertura. In: SIMPÓSIO INTERAMERICANO DE EDUCAÇÃO E CONTROLE DO DIABETES MELLITUS, 1989, Brasília. p. 47.

05. COSTA, M.E.B. A equipe multiprofissional para a assistência ao diabético Participação do enfermeiro. In: ENCONTRO NACIONAL DE EDUCAÇÃO EM DIABETES, 2, 1988, Florianópolis. Anais. Florianópolis: SBEM-SC, 1988, p. 66-81.

06. GONZALEZ, R. B.; PÈREZ, R. S. La educación al paciente diabético. Editorial Ciências Médicas: Habana, Cuba, 1991. p. 39-44.

07. HADDAD, M.C.L. et al. Atendimento ambulatorial interdisciplinar ao paciente diabético. Femina, Londrina, v. 9, n. 8, p. 158-67, dez. 1988.

08. IDE, C. A. C., CHAVES, E. C. A intervenção do enfermeiro na assistência ao diabético. Rev.Esc.Enfermagem USP, v. 26, n. 2, p. 187-96, ago: 1992.

09. LANGE, H. I. Educación para el autocuidado del paciente diabético. Bol.Esc.Med., v. 21, n. 1, p. 32-3, 1992.

10. LUCE, M., PADILHA, M. I., SILVA, M. A. Preparo para o auto-cuidado do cliente diabético e família. In: CONGRESSO BRASILEIRO DE ENFERMAGEM, 41, 1989, Florianópolis.

11. PERRASSE, A. V. Manual del educador en mellitus. Clave Publicitária, 1987. p. 167.

12. POVDA, L. C. In: ZAGURY, L. et al. Diabetes sem medo. /Prefácio/. Rio de Janeiro: Rocco, 1984. p. 112.

13. SÃO PAULO. Secretaria de Saúde. Centro de Apoio e Desenvolvimento das Ações Integradas de Saúde. Programa de educação e controle do diabetes mellitus no SUDS-SP, São Paulo: Secretaria de Saúde, 1991. p.75.

14. SILVA, M.A. et al. Participação do enfermeiro na equipe multiprofissional do plano de educação, controle e prevenção do Diabetes Mellitus noH. U. C. F. F. - R.J. Rev.Bras.Enfermagem, Brasília, n. 2/3, p. 133-44, abr/set. 1992.

15. DIABETES education study group of European Association for the study of diabetes. Genebra, 1985. p. 44.

16. TSUZUKI, S. Sessão de abertura. In: SIMPÓSIO INTERAMERICANO DE EDUCAÇÃO E CONTROLE DO DIABETES MELLITUS, 1989, Brasília. p. 15-7.

17. VIVOLO, M. A. et al. Experiência com colônia de férias para jovens diabéticos: proposta de educação e aperfeiçoamento profissional. Arq.Bras.y Endocrinol.Metab., v. 37, n. 2, p. 64-8, jun. 1993. 


\begin{abstract}
ANEXO I
UNIVERSIDADE ESTADUAL DE LONDRINA

CENTRO DE CIÊNCIAS DA SAÚDE

HOSPITAL UNIVERSITÁRIO REGIONAL DO NORTE DO PARANÁ

PROGRAMA DE ATENDIMENTO AMBULATORIAL INTERDISCIPLINAR

AO DIABÉTICO
\end{abstract}

AVALIAÇÃO

NOME:

RG:

GRUPO:

DATA DA ADMISSÃO NO PROGRAMA:

DATADA AVALIAÇÃO: I

1

IDADE:

RESPONDA AS QUESTÕES ABERTAS OBJETIVAMENTE, E PARA AS PERGUNTAS FECHADAS, ESCOLHE SOMENTE UMA RESPOSTA.

\title{
I - HIGIENE CORPORAL
}

01 - O Diabético deve prestar cuidados especiais aos pés porque?

( ) Os pés chatos são freqüentes nos diabéticos

( ) A Diabetes produz muita calos idade

( ) Com o passar dos anos podem apresentar problemas circulatórios que favorecem o aparecimento de infecções

( ) Não sei

02 - Os melhores cuidados para os pés são:

( ) Cortar as unhas e os calos todos os dias

( ) Tratar calos com iodo

( ) Cortar as unhas retas periodicamente, não usar nenhum produto irritante nos pés e não usar sapatos e meias apertados

( ) Não sei

03 - A escovação dos dentes nos diabéticos deve ser feita:

( ) Uma vez ao dia

( ) Somente antes de dormir

( ) Após as principais refeições

( ) Não sei 
04 - O Diabético deve ir ao dentista:

( ) Pelo menos 1 vez ao ano

( ) Somente quando apresentar cáries

( ) Quando o médico encaminhar

( ) Não sei

05 - Tomar banho morno diariamente é importante porque?

( ) Mantém o corpo aquecido

( ) Evita o aparecimento de infecções na pele

( ) Evita o ressecamento da pele

( ) Não sei

II - EXERCÍCIO FÍSICO

01 -Você realiza algum exercício físico?

Tipo: Duração:

Periodicidade: Cuidados que toma ao realizar os exercícios

(alimentação/insulina):

02 -Qual o beneficio dos exercícios físicos (caminhadas, esportes, etc.) no controle do diabetes?

03 - Quando um diabético realiza um exercício físico de vez em quando:

( ) Se alimentará antes de realizá-lo

( ) Comerá menos durante o dia

( ) Suspenderá a insulina

( ) Não sei

04 - Os exercícios físicos ou as caminhadas realizadas todos os dias:

( ) São bons para os diabéticos compensados

( ) São danosos para os diabéticos compensados

( ) Não auxiliam no controle da diabetes

( ) Não sei

05 - As roupas apropriadas para realização dos exercícios físicos são:

( ) Roupas de lã para aumentar a sudorese

( ) De nylon e apertadas

( ) Roupas leves e tênis - de acordo com estação do ano

( ) Não sei 
06 - Os exercícios físicos devem ser realizados:

( ) 1 vez por semana intensamente

( ) 3 a 4 vezes por semana, durante 1 hora

( ) Em casa, pois o trabalho doméstico é o maior exercício

( ) Não sei

\section{III - APLICAÇÕES DE INSULINA E HIPOGLICEMIANTES ORAIS}

01 - Qual a medicação que você utiliza no tratamento do diabetes

Tipo: Dose: Horário:

Tipo: Dose: Horário:

02 - Cite as ocasiões que você suspende o uso da insulina

03 - Você faz a auto aplicação de insulina?
( ) Sim
( ) Não
Quem faz para você

Em caso negativo, citar o motivo:

04 - Quais os locais que você faz a aplicação de insulina?

05 - Qual a importância de se fazer o rodízio na aplicação de insulina?

06 - Como você adquire a insulina e a seringa?

07 - Onde você guarda a insulina e qual a técnica que você usa para conservar o material de aplicação?

08 - Um diabético que toma insulina necessita:

( ) Tomar insulina todos os dias

( ) Tomar insulina somente quando o açúcar estiver alto

( ) Tomar a insulina em dias alternados

( ) Não sei

09 - Quando um diabético que toma insulina se encontra doente e não tem apetite:

( ) Não deve tomar insulina

( ) Continua tomando insulina e se alimentará com líquidos

( ) Trocará por comprimidos

( ) Não sei 
10 - Um diabético gordo que toma comprimidos:

( ) As vezes pode controlar só com dieta

( ) Pode tomar mais comprimidos para se alimentar mais

( ) Não necessita seguir a dieta

( ) Não sei

11 - Um diabético que toma comprimidos:

( ) Pode trocar os comprimidos sem consultar o médico

( ) Pode necessitar insulina em um determinado tempo

( ) Pode suspender o comprimido sem consultar o médico

( ) Não sei

12 - Quando um diabético que toma comprimidos e tem uma infecção ou outro tipo de descontrole:

( ) Suspenderá os comprimidos

( ) Pode necessitar de insulina

( ) Trocará os comprimidos

( ) Não sei

\section{IV - AUTOMONITORIZAÇÃO}

01 - Qual o local e a freqüência que você verifica seu açúcar no sangue? (glicemia) Local:

Freqüência:

02 - Quais os valores de açúcar (glicose\} no sangue considerados normais?

Em jejum:

Após as refeições: (2 horas)

03 - A taxa de glicemia indica:

( ) A quantidade de açúcar que ingerimos

( ) A quantidade de açúcar na urina

( ) A quantidade de açúcar no sangue num dado momento

( ) Não sei

04 - Os testes de glicose no sangue e na urina feitos com fitas reagentes deverão ser realizados :

( ) Só quando o diabético sentir dor de cabeça

( ) Após as refeições

( ) Em jejum sempre e alternado antes e depois das principais refeições, pelo menos 3 vezes por semana

( ) Não sei 
05 - Qual a freqüência que você realiza o teste de glicose na urina e como você interpreta o resultado?

06 - Como você adquire as fitas para a automonitorização da glicosúria e da

glicemia?

( ) Não realizo automonitorização

( ) Compro a glico fita

( ) Recebo doação de

( ) Outros (citar fonte)

07 - O exame de sangue chamado hemoglobina glicosilada permite avaliar:

( ) As trocas sanguíneas nos vasos

( ) A quantidade de gordura no sangue

( ) Controle do diabetes nos últimos 2 a 3 meses

( ) Não sei

08 - A presença de corpos cetonicos na urina indicam:

( ) Início de hipoglicemia

( ) Descontrole grave de diabetes ( cetoacidose )

( ) Sinais de infecção urinária

( ) Não sei

09 - Quando você realiza a automonitorização da glicosúria e ou glicemia você sente:

( ) Que é um incômodo

( ) Não se importa, pois é importante para seu controle

( ) Acha uma chatice e sem valor para o tratamento

( ) Só faz porque é obrigado a fazer

( ) Dói muito

( ) Só faz quando abusou da comida e quer aumentar a dose da insulina

\section{V - INFORMAÇÕES SOBRE A DIABETES MELLITUS}

Tipo de diabetes: é diabético há quantos anos:

01 - O hormônio produzido pelo pâncreas é:

( ) O Colesterol

( ) O Estrógeno

( ) A Insulina

( ) Não sei

02 - Os sintomas mais freqüentes do diabetes são:

( ) Enjôos e dor de cabeça

( ) Dor de estômago e febre

( ) Sede, fome e urina em grande quantidade

( ) Não sei 
03 - O tratamento do diabetes consiste em:

( ) Tomar antibióticos

( ) Dieta, insulina ou medicamento oral, exercício físico e auto-controle do diabético

( ) Chás e medicamentos naturais

( ) Não sei

04 - O objetivo do tratamento do diabetes é:

( ) Aumentar os níveis de açúcar no sangue

( ) Manter as taxas de açúcar no sangue em níveis normais

( ) Diminuir a capacidade do corpo para usar os alimentos

( ) Não sei

05 - Qual é a ação dos medicamentos para tratar a diabetes?

Comprimido:

Insulina:

06 - A hipoglicemia manifesta-se quando:

( ) Comemos pouco ou aplicamos mais insulina que o necessário

( ) Comemos mais que indicado ou esquecemos de tomar a insulina

( ) Comemos muitos alimentos doces

( ) Não sei

07 - Os sintomas que nos fazem suspeitar de hipoglicemia são:

( ) Tremores, sudorese, fadiga e dor de cabeça

( ) Náuseas, vômitos e febre

( ) Câimbras e dores nas pernas

( ) Não sei

08 - Se você apresentar sinais de hipoglicemia, o que você faz?

( ) Vai ao médico imediatamente

( ) Ingere um alimento açucarado

( ) Fica de repouso até passar

( ) Não sei

09 - Quais os sintomas que você apresenta quando a sua glicemia se eleva de forma moderada, (hiperglicemia)?

( ) Vômitos, língua seca, hálito de maçã passada, respiração profunda

( ) Febre, inchaço nos pés

( ) Urina excessiva, fome importante, sono, queda da visão, glicosúria positiva

( ) Tremores, suores, dor no estômago

( ) Não sei 
10 - Quais os sintomas que você pode apresentar quando o seu diabetes descompensa e a glicemia se eleva muito, de (forma grave - cetoacidose)?

( ) Vômitos, língua seca, hálito de maçã passada, respiração profunda

( ) Febre, inchaço nos pés

( ) Urina excessiva, fome importante, sono, queda da visão, glicossúria positiva

( ) Tremores, suores, dor no estômago

( ) Não sei

11 - O que você faz quando está com hiperglicemia ?

( ) Procura o médico imediatamente

( ) Aumenta a dose de insulina conforme orientação do seu médico

( ) Diminui a dose de insulina ou comprimido

( ) Não sei

12 - O que você deve fazer quando está com cetoacidose?

( ) Procura o médico imediatamente

( ) Aumenta a dose de insulina conforme orientação do seu médico

( ) Diminui a dose da insulina ou comprimido

( ) Não sei

13 - Quais as complicações que os diabetes mellitus pode ocasionar a longo prazo nos diabéticos que não tem bom controle da doença?

Olhos:

Pés:

Rins:

Outros:

\section{VI - ALIMENTAÇÃO}

01 - O que você entende por fracionamento da dieta?

( ) Comer só quando tem fome

( ) Cortar os alimentos em pedaços pequenos

( ) Dividir os alimentos em várias refeições durante o dia

( ) Não sei

02 - As principais fontes de proteína são:

( ) Alimentos de origem animal (carnes, ovos, leite, pescados)

( ) Frutos e verduras

( ) Batatas e arroz

( ) Não sei 
03 - As principais fontes de carboidratos (açúcares)

( ) Frutas e peixes

( ) Aves e verduras

( ) Massas, cereais e batatas

( ) Não sei

04 - As gorduras que menos prejudicam o corpo são:

( ) De origem animal (banha, toucinho...)

( ) De origem vegetal (óleo)

( ) As que se encontram naturalmente nos alimentos

( ) Não sei

05 - Substituir um alimento pelo outro significa:

( ) Deixar de fazer uma refeição

( ) Comer um outro alimento que pertença ao mesmo grupo

( ) Comer frutas no lugar de qualquer alimento

( ) Não sei

06 - Podemos substituir $100 \mathrm{~g}$ de carne por:

( ) Um prato de alface

( ) Dois ovos

( ) Uma porção de fruta

( ) não sei

07 - Uma laranja pode ser substituída por:

( ) Metade de um abacaxi

( ) Uma banana maçã

( ) Um pãozinho

( ) Não sei

08 - Um copo de leite pode ser substituído por:

( ) Um copo de iogurte com adoçante

( ) Um copo de chá

( ) Três copos de leite desnatado

( ) Não sei

09 - Os alimentos dietéticos podem ser usados:

( ) À vontade porque não tem nenhuma caloria

( ) Com moderação porque contém calorias

( ) Somente quando o diabético quer perder peso

( ) Não sei 
10 - Os alimentos ricos em fibras, como frutas, verduras e cereais integrais e outros, são importantes na alimentação porque ajudam a:

( ) Aumentar o colesterol no sangue

( ) Controlar o colesterol e a glicose no sangue

( ) Somente quando o paciente quer perder peso

( ) Não sei

11 - Alguns tipos de alimentos podem ser ingeridos a vontade por fornecer poucas calorias

Estes são:

( ) Verduras (folhas) em geral, chá, água, limonada

( ) Produtos dietéticos em geral

( ) Frutas

( ) Não sei

12 - As pessoas com diabetes devem evitar comer alimentos que levam açúcar na preparação porquê?

( ) Causa hipoglicemia

( ) Aumenta rapidamente o açúcar no sangue

( ) Causa carência de vitamina

( )Não sei

13 - Alguns alimentos ricos em carboidratos (açúcares) podem ser ingeridos, mas com moderação entre os quais temos:

( ) Batata, macarrão, mandioca

( ) Polenta, farinha de mandioca, mandioquinha

( ) Batata doce, arroz, sagú

( ) Todas as alternativas estão corretas

( ) Não sei

\section{VII - ASPECTOS SOCIAIS}

01 - Cite algumas dificuldades que você encontra por ser diabético?

02 - Quais hábitos mudaram em sua vida e de sua família após a descoberta do diabetes?

03 - Você sabe quais os seus direitos previdenciários, sociais, trabalhistas e civis? 
04 - Você participa de algum grupo recreativo?

(idosos, jogos, mães, jovens, etc...)

\section{VIII - COMENTÁRIOS SOBRE O PROGRAMA}

01 - Cite alguns temas que você aprendeu no programa de diabetes:

02 - O que você considera mais importante no programa?

IX - IMPRESSÕES DO ENTREVISTADOR

$X$ - SUGESTÕES

XI - ENTREVISTADOR(ES) 